\title{
Media centre administration: An alternative for success
}

\author{
Thomas L. Russell \\ North Carolina State University, USA
}

\begin{abstract}
Many media centre administrators worldwide regularly experience budget cutbacks or, at least, the threat of cutbacks. If you have not been threatened by the budget slashers, or if you are satisfied by the level of support your media operation is enjoying, your time might be better spent in reading the other articles in this journal: you have likely discovered your alternative for success.
\end{abstract}

This paper will challenge the usual ways of thinking about managing media centres I intend to attack some of the sacred cows of media and media centre management, and to offer alternatives to the commonly accepted operational procedures which have resulted in media centre closings and cutbacks during unfavourable economic times. There may be times when I over state my case, but usually it will only seem so. There are, of course, media centres managed in the commonly accepted ways that are succeeding these days. But is it possible to run a centre in such a way that it is practically assured of flourishing when the economy and support for education in general declines? The answer is, "yes", but it requires change drastic change - from the traditional ways media are perceived. I would like to share with you some successes and failures in media management and the lessons they have taught.

The media centre administrator's/manager's authority - no matter how great - always seems to be significantly less than the corresponding responsibility. This is a fact of life in management: therefore our job as media manager, like those of all other managers, is difficult.

The goals of the media centre should reflect the intention to move the centre in the direction of being indispensable. If the present broad goals include words such as "supplement" and "enhance", it would be wise to 
consider rewriting them. In the endless discussions on defining goals, the archer analogy may be used to illustrate how media centre goals are often established. Likely, you will recall hearing of the archer who fired his arrow into the forest and then painted a target around the arrow on the tree where it had struck. That analogy is most applicable to the way in which many media centres are managed in terms of expending efforts and resources on any project as long as someone is interested in doing it - or came to see you first. Always be at least a little suspicious of the path of least resistance: doing what everyone wants or even what everyone is excited about doing, but is less than enthusiastic about using in a way that justifies the production effort. Also, a good manager is always sceptical of those projects everyone will support without question. That could mean that the project has no real impact if you accept my thesis that meaningful change is a desirable goal and most people, by nature, resist change.

Resistance to change is a human characteristic. John Kenneth Galbraith is credited with saying, "Faced with the choice between changing one's mind and proving that there's no need to do so, almost everyone gets busy on the proof". Since the establishment of the first media centre, media practitioners have - like it or not - been tabbed as agents of change. Often, therefore, they are looked at with suspicion and as bearers of the promise of work: because change, at the very least, means work. Those of us in media have established our own traditions, and are often as prone to rigidity and resistance to change as are those we criticise. At the same time, we must remember the past, trying not to repeat our errors while not disregarding the possibilities that different approaches can alter events.

Since the advent of technology, we have tended to embrace the latest development, proclaiming the arrival of the next panacea and virtually dropping the past and immediate past panaceas before they had a chance to develop. Most innovations go through a shakedown period fraught with predictable failure. As a result, these failures loom large in memory. What comes to mind when you hear "programmed instruction", "language labs", or "dial access" ? Now hear "mini-computers", "interactive video" and "teleconference". But how then can we determine success?

"Quality" is the word we most often use to describe the general characteristic we ascribe to the contribution media make to instruction. That in itself is fine and, although difficult to prove, I, too, believe we do a great deal - not always planned - in that direction. But too often we define "quality" in terms of visuals added, time and money spent, special effects, or whatever. If we are able to diminish the emphasis on the difficult-todefine "improved" argument, then we can look to specific characteristics of media to justify our existence. 
For well over 30 years, the results of research on the effectiveness of instructional technology, when compared with the traditional classroom approach, can be boiled down to the often maligned phrase, "no significant difference". For too many years, we in educational media have scoffed at these results and pointed to occasional studies which supported our contention that media somehow make it better. Our detractors can and do, unfortunately, point to contrasting studies of equal number where the media side lost. At either extreme, it seems inevitable that uncontrollable variables can be easily identified which respective antagonists can point to in order to dismiss the results detrimental to their positions. I fear this will always be the case unless someone can do the impossible and find a way to control all variables in human learning research as can be done with rats or pigeons. Until that time, I see no alternative but to accept the fact that "no significant difference" is the one conclusion that is acceptable to most from the vast body of research. So, what is so bad about "no significant difference"? It is not bad at all when economic times are good and everyone "knows" or "feels" media are a fine enhancement to learning, and we are tolerated as expensive supplementors to the established traditional modes. But when the economic climate is not so hot, what then?

We can state emphatically that, at the very least, media do not detract from instruction. People learn at least as well. Rejoice, for we can now look to exploit the efficiencies media can bring without diminishing the quality of instruction. Media properly applied can reduce the cost of instruction, increase the number of students reached, and provide instruction where it is needed, when it is needed. I emphasise the phrase, "media properly applied", from the preceding statement. Despite what we want or what we profess, far too many instructional programs, by the sheer weight of traditional production people and procedures, are destined to become ends in themselves. The program objectives and, of equal importance, program utilisation needs often take a backseat to the medium itself.

Doing the best job possible with a specific program is not necessarily doing the best job of management. Care should always be taken to balance the production effort against the utilisation value. While on the surface it may seem folly to criticise one who professes to do "the best job possible" in favour of one who intends to do the "best job necessary", that is exactly what we should do. Of course we must still do a good job for, to be sure, our glaring mistakes are not likely to be overlooked. As mentioned earlier, far too often the innovative aspect is the only one attended to when things go wrong. We are still the new kids on the block, so narrow persons can point to our failures and blame the introduction of the media. Yet, there have been and, unfortunately, continue to be some disasters in the traditional classroom, but no one blames the classroom. 
Some of our colleagues who had previously read journals like AJET are not reading them these days. Indeed, you may know of a few who are presently unemployed or re-employed in a different line of work, having watched their enhancement/supplemental media empires tumble under the budget cutters' axes. I know how they feel. In most of these cases, the educational programs in their communities continue to function with little notice of their absence.

One point before I proceed: even though I have had and continue to have responsibility for all manner of media in my professional life, I have found myself repeatedly favouring television in its many facets as a medium most easily applied to many fiscally accountable tasks in education. So I have decided to get off the bandwagon and concentrate on television. My bias is supported by the thesis that television is the one medium capable of blending virtually all other media, and delivering the resulting instruction over the airways, by wire, or by conveyance in prerecorded packages. Television has the characteristics necessary to best fit my image of an economically viable medium. Therefore, my illustrations will come from television experience; however, the principles apply to all media.

My initial orientation to television production was through the traditional route. I learned, and later practiced, the commercial broadcasters' studio production techniques and was a true believer in the Bible according to Stasheff, Bretz, Zetyl, et al. I produced many, many programs: the obligatory student news "show"; the "celebrity" interview; and the highly produced instructional specials and series. I laboured many an hour over preparing scripts, ordering graphics, getting slides, films, and props. I conducted crew training, rehearsals and editing sessions. I bought equipment, lamented about the new equipment I couldn't afford, and panicked when the equipment I did have wouldn't work. I eventually found myself with an impressive list of slickly produced program credits, widely praised. The facility we built, linking 60 buildings to our broadcasttype studios, was the envy of many. You can imagine my disappointment when I had to oversee the dismantling of the system and release of the staff. The teachers' union, in a salary dispute with the board of education, was asked by the board for their recommendations as to where funds could be found. They replied with a list. Television was near the top of their list of "frills" they could forego.

Then, another opportunity came to display my expertise. When I was asked to produce a series of taped lectures to be delivered to engineers in industry so that they could take college courses at their job site, I remained consistent to the belief that we had to produce scripts, slides, and all the rest. I repeated all of the catch cliches I had learned from many respected leaders in the field: "Beware of the talking heads"; and "Balk at talk and chalk". After all, how many times have you heard expressed the sentiment, 
"On television, avoid talking heads at all costs"? I've even heard my colleagues boast of accomplishing their goal of getting the talking heads off the screen entirely, or nearly so. As one of the staunch anti-talking heads men, I laboured over many a production looking for opportunities to add some slides, or a piece of film. At professional meetings, I enjoyed joining in the blanket denunciation of all talking heads. I even used to use the cliche, "One picture is worth a thousand words", until much later when I realised that some words defied accurate conveyance by even the greatest art department.

I now believe such a rigid, single-minded position to be dangerous and potentially counter-productive. Admittedly, much of educational/ instructional television has been, and to a large extent continues to be, of poor quality. But I reject the blanket criticism that the reason is simply too many "talking heads". Nevertheless, at that time I continued to place the greatest emphasis on highly produced programs. Some of these programs were successful; others didn't quite make it despite the abundance of elaborate sets, film inserts, slides, demonstrations - you name it we used it. Then came a request from the extension centre for our unit to videotape a series of speeches to be given to a management seminar off campus. Naturally, we were not thrilled with the idea of taping speakers when all they were doing was talking and possibly using a chart or chalkboard yes, talking heads! For political reasons, we were trapped so I reluctantly agreed. Since we did not have a sophisticated remote facility and because of our lack of enthusiasm for the project, it was understood that the production unit would consist of a single camera, one microphone, and a small format video tape recorder. Further there would be a staff of two: a student camera operator and a technician.

The project continued as scheduled with predictable results, but there was one notable exception. On one occasion we experienced the whatever might-go-wrong-will-go-wrong syndrome. The tape machine was acting up, we were unable to get our regular camera operator, and the substitute was an inexperienced one - I think his name was Murphy. The camera was not performing properly, the speaker refused to allow additional lighting, and he was using a chalkboard that was too low. After the tape was completed, we sat down for a screening. What we saw was a technical fiasco. We couldn't see everything on the board due to the heads of the audience, and the speaker occasionally walked out of the frame. Zooms and pans - not to mention focus - were shaky and otherwise awkward. We were most concerned about our reputation and tried unsuccessfully to withdraw the tape from the playback schedule. Imagine our surprise when the audience for our first playback made such statements as, "a fine program", and "the best of the series". No one complained about the obvious - to us - technical flaws. 
We sat down once more with the tape to try to figure out the reason or reasons for this positive response to a terrible tape: this time we looked at the program, not the tape. It was still a terrible tape but it was an excellent program because the speaker was an outstanding speaker, and what his talking head had to say was significant, well-prepared, and very wellpresented. Despite the so-called "fact" that today's audiences are conditioned by broadcast television of high technical production standards, the usefulness of the content and the teaching competence of the presenter while in his natural environment superseded the technical flaws. Even more importantly, the subsequent repeated use of this tape suggested to me that a change in priorities was in order.

When producing instructional television programs, I often hear producers use "the networks" or "commercial television" as the attainment level they aspire towards - their standard of excellence. At worst, the resulting programming can be an embarrassingly poor carbon copy. At best, we could end up with an expensive "success" which receives accolades from our colleagues, but spends the rest of its life on the shelf or as a supplement to the teacher. Once the novelty wears off, this kind of success has been known to haunt one when the budget cutters compare the investment with the utilisation. There is another problem when using the traditional commercial model. With few exceptions, even a poor, commercially-produced example includes on-camera performers who have talent. And their talents, even the poorest, are usually far ahead of the performance talents of our best teachers. Therefore, we all too often end up with marvellously produced programs featuring sterile, stiff, amateurish people.

There must be a better way. There are many ways. But first, we must be ready and willing to accept reality. We must be imaginative and innovative and challenge the edicts of those who have become smug in their ivory studios blessed with situations that apparently do not truly hold their feet to the accountant's fire. Most of us already possess all of the necessary tools to do the job and do it well. While it is true most of our teachers will never be good performers by the network standards, let it be enough that we expect them to be good teachers. Yes, media, as traditionally applied, make new requirements of teachers. Why not allow our teachers to make new requirements of media? There are numerous seminars and workshops all over the world which continue to preach the gospel according to $\mathrm{ABC}, \mathrm{BBC}, \mathrm{CBC}, \mathrm{NBC}$, and PBS. Many continue to worship at these altars without realising that the obvious and traditional route - the "network" model - is the least likely of attaining a fiscally viable program.

Many of us spend a great deal of effort, rightly so, in trying to convince teachers of the importance of media. Don't overlook the administration. 
Do we need the support of the teacher? You bet we do. But even more importantly we need the real support of a good administration. I say "good administration" because I recognise this to be a major problem in many school and university systems. However, one small triumph with administration can be worth a barrel full of teacher triumphs.

Support by the administration is the key to success. Support is usually defined in terms of facilities and staff. Many of us feel lucky if we have that! But that is only one dimension and it is not enough. Even the most elaborately staffed and equipped media centre cannot go far on that alone. The administration - even the weakest - provides the all-important reward and punishment system. If the academics know that their efforts with media are truly appreciated by administration, they will use it. And, of equal importance, should they choose not to employ media when it is desirable to do so they likewise are accountable. The support provided by administration should not only provide the resources and time, but minimise the risks when witnessing this phenomena on more than one occasion.

Shortly after a new dean was appointed at a school in a large northern college in the United States with which I was affiliated, I witnessed an astonishing bit of administration I never thought could happen. At one of his first meetings with his academics, the dean announced that he was anxious to have them active in a variety of projects along with classroom teaching and research. He proceeded to read a list of their names with specific assignments which ranged from writing texts to committing courses to television. He went on to explain that all of these possibilities existed all along and that he was going to eliminate one alternative that they had been enjoying - to do none of them. After the hubbub and voiced objections had subsided and after he offered to write letters of recommendation for anyone wishing to resign (and he meant it), he continued: he pledged his wholehearted support - both money and time for all of the projects. Of equal importance, he assured them that he would stand by each person even if the assignment turned out to be less than totally satisfactory, providing that each person gave their best effort to their own project. Needless to say, there was less than total acceptance and a great amount of unrest. After a short while, all projects were underway and no one resigned. I witnessed, on the part of those working on the media projects, a seriousness and receptiveness to ideas far greater than I was used to. As projects were completed, the positive reinforcement factor took over and the momentum was unstoppable. What's best, the academics in that department discovered capabilities they didn't know they had and probably never would have known they had. Within a matter of months, the project output from the faculty in that school and their morale were the highest on campus. That, too, happened at one of those difficult economic times which come about all too frequently in the academic world. 
Finally, I came to realise that there was in fact a way to weave the media centre into the fabric of the system in such a way as to make media fiscally irreplaceable. I laboriously pondered the previously mentioned and related experiences coupled with the realities they revealed. The resulting policies were then determined based on the goal of creating and maintaining media's place as indispensable to the system.

I set out to create a recession-proof media centre. We started developing ways of identifying costs of education in general and ways media could be used to reduce those costs. We began to seek out and fully support only those projects with promise of having the greatest impact. We did continue to produce elaborate programming; however, the full support of the media centre was only given those projects that were assured of being cost effective.

To assure that production costs would be totally justified, a simple budgeting system was devised. The first questions asked pertained to the ultimate use of the finished programs, especially whether or not the committed utilisation would save time, money, and so on. If the project under consideration was primarily supplementary in nature, therefore cost-added only, then all production costs were to be provided by the client and the project would be assigned a low priority in the media centre. If, however, the project could promise a cost benefit, then the figuring began. First, we would gather accurate figures on the present and projected costs for providing the instruction as it was presently being done without media. Second, all costs of administering the finished mediated series for the anticipated life of the series were determined. Finally, we subtracted the mediated costs from the unmediated costs. The difference represented the production budget. If that bottom line figure was judged to be too low in terms of client-expressed requirements, then the project was cancelled unless outside support and/or other justification, such as a defensible quality improvement argument could be identified. If the final figure proved satisfactory, the production proceeded.

This policy, judicially applied, is fiscally responsible and demonstrates to administration that the media centre is an asset. Even during difficult times the media centre continued to get significant budget increases and new staff positions.

Let us remember we are first and foremost educators. We must identify those elements of education and those of media that, when combined, will result in a media-based educational product designed to do a specific job within realistic budgetary limitations. This approach will be temporarily disruptive to many educators and media managers. But unless we are willing to consider change in our own ensconced traditions, how can we expect teachers and administrators to make necessary adaptations? The 
good teachers know they are doing something right. Let us start from there and not try to change them totally into something they are not or might not be able to become. Our methods and procedures are not cast in bronze. We can take these procedures and corresponding components apart and reassemble them literally and figuratively in a way our judgement and the job at hand demand. Let us stop blindly imitating and start innovating, consciously imitating only what is worthy of our goals. Many of us are critical of the tradition-based institutions which stand in the way of our media interests. Not many of us in media are critical of the very same kind of traditions that have become equally ensconced in our own profession. If we hope to be listened to, we have to listen and practice what we preach: change!

I would like to illustrate what I have been saying by telling you about one very successful project. This project was devised as a means to achieve the objective of providing undergraduate and graduate textile courses at textile and related companies anywhere in the United States on a continuing basis. It was believed that such courses, regularly offered at the College of Textiles at North Carolina State University, U.S.A., were needed by full time textile employees unable or unwilling to go to the college to attend classes. Existing traditional methods of achieving this goal were too costly and cumbersome especially since the system had to be designed to reach relatively few enrollees spread throughout the nation. Since the potential off-campus enrolment was very low, the operational costs of providing these courses needed to be modest, especially since the project had to be self-supporting.

It was decided that the only feasible way to meet these goals was through the distribution of course information using videocassette technology. However, this determination introduced a number of new problems. Time and the need for immediacy, would not permit a typical, rehearsed studio production. Members of the administration and teachers insisted that the system must not, in any way, detract from the quality of instruction given on campus students. Moreover, the instruction reaching off-campus students via videocassettes would not be allowed if it were second rate. Solace was taken in the fact that other major universities had experienced significant success recording classroom lectures during regularly scheduled class meetings. After extensively researching these types of systems, it was decided that a similar system would be established at the College of Textiles. Since the size of the potential enrolment was small, the planned facility had to be considerably less expensive to install and operate than any of the other comparable systems. Also, from our perspective, all of the existing systems had shortcomings which had to be isolated and corrected.

At the hub of the project, a unique lecture/recording facility called the studio/classroom was developed. The very design of this facility is the 
primary reason for the academic and cost effectiveness of the system. The basis for this studio/classroom was an existing, conventional, virtually abandoned television studio that was disassembled, augmented, and reassembled with a purpose in mind. (Incidentally, this conventional studio's abandonment was the result of conventional management). Many unique characteristics have been incorporated into this facility. For example, it was determined that due to cost only one operator could be used. This operator performs all functions usually handled by at least four or five persons in a conventional studio setting. We found a ready pool of competent operators among our students eager to participate in a demanding and responsible capacity. These operators function as switcher, camera operator for three cameras, floor manager, engineer, videocassette operator, and projectionist. It follows, then, that a monitoring and control design had to be devised that reduced the complexity of these chores - and at minimum cost.

The necessity of keeping operating costs low precluded the availability of a full-time maintenance engineer or technician, yet it was imperative that the system be extremely dependable and that the recordings be of high quality. Therefore, a totally redundant system was established. For example: There are two complete sets of lights on separate circuits; if one light fails another can be turned on by the operator to light the affected area. Although the system can function adequately with two cameras, three are provided. Video monitoring is set up in such a way that if a monitor fails, the lost signal can be fed to a backup monitor. Back-up also exists for videocassette recorders, audio, and all other components in the system.

As previously mentioned, three cameras are used. Two of the cameras, equipped with manual zoom lenses, are mounted on fluid heads within easy reach of the operator. The third camera, remotely operated, is mounted above the instructor and focuses on the surface of a special desk. Using this camera, the instructors can control their use of illustrations, notes, demonstrations, overhead transparencies, and samples.

The on-campus students in the room watch the images from the overhead camera on large monitors in the front of the room. The instructor sees the same picture on an identical monitor at the back of the room. In this way the instructor can adjust what is on the camera and may even instruct the operator to zoom in or zoom out. In addition, every time the instructor checks the monitor, approximate eye contact is achieved with the offcampus students since one of the cameras is located next to the monitor. Note that all of these room monitors usually show only what appears on the overhead camera; and, therefore the instructor and on-campus students are never distracted by superfluous (to them) images intended for off-campus students. 
Adequate illumination is accomplished using only three lighting fixtures for the instructor's area and a fluorescent bank for the students thereby assuring a comfortable, normal appearing room. As mentioned earlier, a set of back-up lights is available at the flip of a switch.

The instructor is encouraged to use all media appropriate to the presentation. In addition to those media already mentioned, the instructor can use the chalkboard, although use must be limited to prescribed areas of the board. Filmstrips, $35 \mathrm{~mm}$ slides, and $16 \mathrm{~mm}$ films can be projected onto a screen in the front of the room and picked up by one of the manual cameras. This allows the use of all slides (vertical as well as horizontal) and films while avoiding film chain cropping problems. Since most slides were not designed for television use, the operator can compensate by panning and zooming on the projected image. Instructors are encouraged to use a greater variety of media than usual since projectors (slide, filmstrip, and film) are always set up and the operator also functions as room projectionist, saving the instructor the chores normally associated with acquiring audiovisual equipment and its operation. Provision has also been made, via a separate videocassette player, to include the input of pre-recorded video segments.

Directional microphones are used to record on-campus students' questions and discussions in order to provide the off-campus student with the complete classroom experience.

In contrast to the feelings evoked in a typical television studio setting, an instructor-controlled classroom atmosphere prevails. This unscripted, unrehearsed informal approach has resulted in relaxed and comfortable faculty eager to offer their courses on the system. Their casual approach is evident from the initial reactions of first time off-campus students. Comments have frequently been made in regard to how much more enjoyable the tapes are than had been expected. One of the ways this informality is achieved is through deliberately casual communication between the instructor and studio/classroom operator when necessary. The operator is trained to ask the instructor to write larger, repeat a question, or to make any adjustments as necessary during the recording. Conversely, the instructor can sometimes be heard to direct the operator to zoom in or back if necessary.

The policy on tape erasure is probably one of the most significant and controversial features of the program. All recordings are shipped, unedited within 24 hours. When tapes are returned three weeks later, they are used for new recordings, not shelved. The stated reason for this is the desire for the material to be current. Also, erased tapes avoid the question of rights. Initially that policy was a necessary concession made reluctantly, in order to overcome instructor resistance, but I am convinced it is the primary reason the instructor's performance is so natural almost from their 
very first recording. Now we find an ever-increasing number of faculty requesting that their tapes be retained.

One question frequently asked pertains to the attitudes of the on-campus student in the studio/classroom with the instructor during recordings. The on-campus students generally express their satisfaction with the studio/classroom. They often cite the advantages they get from some of the interesting things instructors do with the overhead camera. Another benefit these students cite is that they have the opportunity to view tapes for review and make-up. For every location where a course is running, a separate videocassette is made and sent. One more recording than required for off-campus locations is made and placed in the school library for use by on-campus students.

This system has come to be known as Teacher Oriented Televised Education (TOTE). It is teacher oriented in that it is attractive to teachers and they generally participate enthusiastically.

There were many other problems faced and resolved in establishing TOTE. Instructor visits to off-campus students, telephone office hours, assignment grading, exam monitoring, and course laboratory sessions were problems resolved by ordinary and innovative means. So, not only was the studio/classroom created by reorienting the components of a traditional television studio and classroom, but all other aspects were restructured accordingly. What is most important is that new systems can be created by restructuring just the existing elements.

Although difficult to prove, there is general agreement that the quality of instruction that is presented in the TOTE facility is better than in a standard classroom. There are several reasons for this conclusion: the fact that it is being recorded, the maturity and seriousness of the off-campus student, and the easy access to audiovisual equipment.

The marketing of this project is another key element contributing to its success. Potential participants are told this is not a television project, it is a classroom project with the videocassette medium selected to deliver the classroom to the student. The TOTE student should expect a college course just as it would be on campus. He should not expect to be entertained nor should he expect "network" production standards. It is guaranteed that he will get everything - all information - that he would have received on campus. Initially, many potential off-campus students are concerned about the fact that they cannot ask questions during a class, but after their first course most come to agree that this loss is more than compensated for by telephone hours, others asking questions, and especially the ease of review of the tape. Many actually state they are often grateful they did not have the opportunity to interrupt with a specific question. And they certainly appreciate the trade-off convenience of having the course on videocassette 
since the course is delivered to them and they determine their own schedule.

After more than 12 years of operation, there seems to be no doubt that TOTE concepts and systems are sound. This project started in 1976 with just a few students enrolled in one course at one off-campus location. Now the average is 158 students spread out among 14 courses at 56 different locations all over the nation (and occasionally abroad). Seventy-nine percent of the present teaching staff has voluntarily offered courses on the system.

Many media centres will not only survive, but thrive now and in the future if we make the necessary changes to place our media centres right where they belong: at a critical place in the centre of our parent systems. Media centre managers should always be running at least a little scared, constantly asking themselves the question, "What would happen to our institution if the media centre operation were discontinued?" Our everyday decisions should be based on their long range effects on the entire school, university, or company and not on the short range benefit of glossy but supplementary projects. We neither need nor want to disregard all that we have learned regarding production values, all that we have learned from courses, workshops, and journals. But we must reprocess this information in imaginative ways, picking and choosing those components which are fiscally and educationally responsible and appropriate to the task at hand.

When considering an instructional project, be sure to give the ultimate use of the completed project top priority. Avoid committing scarce resources to projects which have little chance of maintaining or increasing the media centre's importance to the system. Be wary of those projects that reinforce your image as a manager of expensive but expendable ventures.

In summary, when designing or augmenting a media centre, here are some questions one should ask before writing the first requisition:

1. What are you going to do with it?

2. Can you afford to maintain and staff it?

3. What problems does it create?

4. Does the facility fit the need? ... will it?

5. How can you demonstrate cost effectiveness?

6. If, two years from now, your media centre is closed down ...

a. will anyone notice?

b. will any services cease that cannot be picked up elsewhere or done without?

Now that you have a facility, projects need to be considered, first, in terms of how they will be used and who will use them, before you even consider 
when, if and how they will be produced. Most useful information can be generated and decisions made from questions, such as:

1. Who, where, and how will it be used?

2. When is it needed? (Can you make the deadline?)

3. Do you have the facilities/time/staff to meet that expectancy?

4. What is the client expectancy in terms of production standards?

5. Will the intended audience have access? (equipment, time, etc.)

6. Will they use it? Why should they?

7. Who will benefit? ... how much? (Is it worth it? Can it be done better and / or cheaper some other way?)

8. Are the clients being realistic regarding the worth of the project? Are they exaggerating?

9. Is there a potential 'payback', and is it at least equal to the investment?

Frequently, education is in a fiscal crisis that often causes a great deal of hardship, but which can ultimately prove to be the best thing that could have happened for the true innovator. Change can most easily occur during times of crisis as those comfortable traditions which resist change falter under their own weight. Technology can play a major role in helping education through difficult times. All we have to do is to realise our true worth and the promise of those exciting media we know so well.

Please cite as: Russell, T. L. (1988). Media centre administration: An alternative for success. Australian Journal of Educational Technology, 4(2), 146159. http: / / www.ascilite.org.au/ajet/ajet4 / russell.html 